\title{
Circuit
}

Musiques contemporaines

\section{Foi et création : une reconnaissance}

\section{Gilles Tremblay}

Volume 5, numéro 1, 1994

Gilles Tremblay : réflexions

URI : https://id.erudit.org/iderudit/902083ar

DOI : https://doi.org/10.7202/902083ar

Aller au sommaire du numéro

\section{Éditeur(s)}

Les Presses de l'Université de Montréal

ISSN

1183-1693 (imprimé)

1488-9692 (numérique)

Découvrir la revue

Citer cet article

Tremblay, G. (1994). Foi et création : une reconnaissance. Circuit, 5(1), 19-21. https://doi.org/10.7202/902083ar d'utilisation que vous pouvez consulter en ligne.

https://apropos.erudit.org/fr/usagers/politique-dutilisation/ 


\section{FOI ET CRÉATION}

\section{Une reconnaissance}

Conférence prononcée à l'occasion des Journées universitaires de la pensée chrétienne, octobre 1973, Université de Montréal. Paru in Les mutations de la foi chrétienne, Montréal, Fides, 1974.

J'ai choisi deux textes en frontispice, pour exprimer un peu mieux ce que j'ai à dire ce soir :

Que les fleuves applaudissent, que les montagnes éclatent de joie.

Psaume 97

En mon Aimé j'ai les monts, les solitaires et ombreuses vallées, les îles prodigieuses, les fleuves au bruit puissant, le sifflement des vents porteurs de l'amour.

Et j'ai la nuit accoisée qui laisse deviner le réveil de l'aurore, le concert silencieux, la solitude sonore, le souper qui recrée et qui énamoure.

Jean de la Croix, Cantique Spirituel, XIV-XV

Quand on m'a demandé de venir ici pour dire, pour parler de la « foi pour moi », c'est-à-dire de la «foi pour nous», cela a eu un certain avantage, celui de m'obliger à m'arrêter à travers le flot de la vie, le bruit dans lequel nous vivons, pour réfléchir un peu plus moi-même sur ce qu'est la foi pour moi. Je vais donc essayer de vous en parler le plus spontanément possible.

Pour moi, ce qui me stimule le plus dans la foi, c'est l'idée d'un Dieu Créateur. Toute la création est signe de son Être et en ce sens sacrée. Ces signes provoquent chez l'homme qui procède de la même poussée et souche créatrice, un Hallel à Yahvé, car il reconnaît son Créateur.

Cet Alléluia lui-même devient à son tour signe sacré. Chant, tracé, écriture de la créature, donc venant du Créateur et retournant au Créateur, en un dialogue ineffable où la créature, à sa manière, épouse le geste du Créateur. J'y vois l'origine de tout art au sens le plus large du terme. «En Toi se trouvent toutes mes sources, 》 dit le psalmiste. Une phrase de saint Jacques traduit 
admirablement cet enthousiasme dans une formule poétique extrêmement ramassée et immense à la fois. Je cite de mémoire: "Tout don vient de Dieu Créateur des étoiles, notre Père à tous ».

Même si cette reconnaissance dont je parlais tout à l'heure, reste cachée chez certains, l'enthousiasme premier, originel, n'en reste pas moins poussée créatrice, donc signe du Créateur. C'est pourquoi je crois que tout art a un aspect sacré authentique, qu'il soit tracé par l'homme des cavernes, celui de l'antiquité ou l'artiste contemporain, même s'il se juge incroyant. Cela aussi fait partie de la foi pour moi. J'aime assumer ce mouvement de foi, même lorsque la reconnaissance reste cachée.

Tout à l'heure M. Michel Dansereau a cité Béjart, je pourrais moi-même le citer encore une fois, Béjart qui dit qu'il ne peut pas y avoir d'art sans foi, je ne dis pas technique mais bien art.

Dieu Créateur est aussi Amour et Verbe: «le Verbe s'est fait chair parmi nous", un homme, Jésus-Christ, et à cause de cet Amour je crois à la vie éternelle, à la résurrection. Je crois également au pouvoir de transfiguration de la foi et de l'amour, au pouvoir de la communion, autrement dit je crois que la foi, l'amour et la communion entre les hommes, ont un pouvoir de transfiguration, de transformation.

Je ne crois pas à une espérance lointaine d'un monde qui ne serait que futur, que l'on attendrait patiemment dans une obscurité, dans un clair-obscur actuels. Je crois au contraire à une espérance assumée, présente à une transformation par l'Amour, incarnée dans le présent. La fuite du présent m'apparaît comme une démission, comme le contraire même de l'incarnation, et peutêtre, quelquefois, ce qui aurait pu dégoûter une certaine partie des personnes qui sont hors de l'Église - en tant qu'image quelquefois projetée de l'Église. $\mathrm{Si}$ je dis, je crois en un seul Dieu, on pourrait me répondre comme saint Jacques: "Tu crois qu'il n'y a qu'un seul Dieu, tu fais bien, mais les démons le croient aussi et ils tremblent. Veux-tu comprendre, homme vain, que la foi, sans les œuvres, est stérile. De même que le corps sans âme est mort, ainsi la foi sans les œuvres est morte.»

Pour moi donc il y a deux points qui sont des points saillants, des crêtes: c'est l'idée du Dieu Créateur et la joie de savoir qu'il y a un Dieu CréateurPère. La deuxième idée, c'est qu'il doit y avoir un accord entre la foi et les actes ou les œuvres, sinon c'est la mort, la mort de la foi, c'est même de I'hypocrisie. 
Je rêve d'une expression religieuse qui soit de mode prophétique et intuitif, poétique, où le rationnel n'ait pas le monopole de la relation mais où la fulgurance éclaire d'un éclat nouveau et antique à la fois les sources de notre foi. C'est pourquoi je termine ce court exposé par ces images enthousiasmantes du psalmiste: «Que les fleuves applaudissent, que les montagnes éclatent en cri de joie». 